\title{
Tidal expiratory flow patterns in airflow obstruction
}

\author{
M J MORRIS AND D J LANE \\ From the Department of Chest Diseases, Churchill Hospital, Oxford
}

\begin{abstract}
Tidal expiratory flow pattern was analysed in 99 subjects with a view to assessing it as a quantitative measurement of airflow obstruction. Fifteen normal volunteers, nine patients with dyspnoea referred for investigation in whom airway resistance was within normal limits, 24 patients with restrictive lung disorders, and 51 patients with airway obstruction were studied. The expiratory flow pattern against time had a quadrilateral configuration in airway obstruction, which differed from the more sinusoidal form that is seen in subjects without airflow obstruction. The rapid rise to tidal peak flow was analysed in two ways, percentage of volume expired at tidal peak flow $(\Delta \mathrm{V} / \mathrm{V})$ and percentage of expiratory time to tidal peak flow $(\Delta t / t)$. Both these indices correlated significantly with conventional measurements of airway obstruction. The pattern of expiratory flow in airflow obstruction during quiet breathing resembles that of a forced expiratory manoeuvre at similar lung volumes. In some cases this way be caused by dynamic compression occurring during tidal breathing. In others the pattern may result from the static recoil of the lung being permitted to drive flow freely in expiration, rather than being braked by postinspiratory contraction of inspiratory musculature.
\end{abstract}

There are many methods of assessing airflow resistance quantitatively. The most popular are the indirect methods involving forced maximum expiratory effort. These have the disadvantages of requiring the patient's full co-operation and coordination and of being influenced by mechanical properties of the lung other than those of the airways. Furthermore, the state of the airways during a forced maximal expiration is not necessarily representative of their state during tidal breathing. In the past, oesophageal pressures have been used to estimate alveolar pressures, and concurrent flow measurements used to obtain resistance. Direct measurement of airway resistance is now usually made by body plethysmography. Other techniques include the interrupter method and the forced oscillation method. Some of these direct methods require expensive complex equipment. In some cases co-operation from the patient is required-for example, panting-and the patient may be subjected to discomfort such as sitting in a closed box or swallowing an oesophageal balloon. Patients usually need to be able to sit at the equipment. Because of these disadvantages it seemed worth while to direct attention to the tidal expiratory flow pattern to see if this could

Address for reprint requests: Dr MJ Morris, Department of Chest Diseases, Churchill Hospital, Headington, Oxford. be used to assess patients who are for some reason unable to perform other recognised tests of airway narrowing satisfactorily.

\section{Methods}

A recording of flow and volume during tidal breathing was taken in 84 patients attending for lung function tests requested by their own doctors. In addition tidal flow pattern and full routine lung function tests were carried out on 15 normal volunteers. The subjects were divided into three groups for the analysis. Group 1 consisted of 15 normal volunteers plus nine patients with dyspnoea, in whom lung function was essentially normal. Group 2 contained 51 patients with airflow obstruction (clinical diagnosis, asthma in 28 , chronic airways obstruction in 23). Group 3 comprised 24 patients with restrictive lung diseases (diagnosis kyphoscoliosis in 19, chronic sarcoid in one, lung resection in two, congenital cystic disease in two). The narrow spectrum of restrictive disorders studied occurred because measurement of diffusing capacity was not available in our laboratory. Most of the patients with kyphoscoliosis were children. Details of these patients and their pulmonary function on the day of study are given in table 1 . 
Measurement of forced expiratory volume in one second $\left(\mathrm{FEV}_{1}\right)$ and forced vital capacity (FVC) were made with a Vitalograph spirometer. FEV $_{1}$ / VC ratio used the maximum vital capacity recorded. Slow vital capacity (VC), inspiratory capacity (IC), and expiratory reserve volume (ERV) were measured with the patient seated in a constant volume whole body plethysmograph (Fenyves and Gut, Basle) breathing through a heated pneumotachograph (Fleish no 3). Flow was integrated to give volume, and the signals written out on an X-Y recorder (Houston Instruments 2000). During tidal breathing, measurements were made of inspiratory airways resistance (Raw) at a flow of $0.51 / \mathrm{s},{ }^{1}$ and of functional residual capacity (FRC). ${ }^{2}$ Total lung capacity (TLC) was calculated by adding inspiratory capacity (IC) to FRC. Predicted values for lung volumes are taken from Bates et al. ${ }^{3}$

In 46 patients with airflow obstruction maximum expiratory flow-volume loops were written out on the $\mathrm{X}-\mathrm{Y}$ recorder. The flow characteristics of this recorder are not fast enough to record the peak flow but are accurate at lower flows, so that a qualitative assessment of the expiratory flowvolume loops in relation to expiartory tidal flows could be made.

During quiet tidal breathing through the pneumotachograph, a recording was made of flow and of volume against time $(10 \mathrm{~mm} / \mathrm{s}$ paper speed $)$ on a Brush 260 recorder (Gould Ind Inc). Ten consecutive breaths were analysed in two ways-(1) percentage of expiratory volume expired by the time the tidal peak expiratory flow rate had been reached $(\Delta V / V)$, and (2) percentage expiratory time taken to reach tidal peak expiratory flow $(\Delta t / t)$. If a plateau of tidal peak expiratory flow occurred, the time to reach the midpoint of the plateau was taken. The average tidal expiratory flow, breathing frequency and percentage of breath time ( $T$ total) spent in expiration (Tex) were calculated on the same 10 breaths.

\section{Results}

Details of the patients and their lung function are given in table 1. A characteristic pattern of expiratory flow was observed in patients with airilow obstruction. Some typical tracings are shown in fig 1. It can be seen that there was a rapid rise to peak flow, followed by an almost linear decline in flow rate over the rest of expiration. Expiration ended while there was still a measurable expiratory flow, when an almost instantaneous decrease to zero flow heralded the onset of inspiration. This 
differed from findings in normal subjects and of patients with restrictive disease in whom the flow pattern had a more sinusoidal appearance (fig 2). The analysis in terms of $\Delta t / t$ and $\Delta V / V$ is an attempt to quantitate these differences in pattern. Figures 3,4 , and 5 and table 2 show that $\Delta V / V$ cor-

Expiration

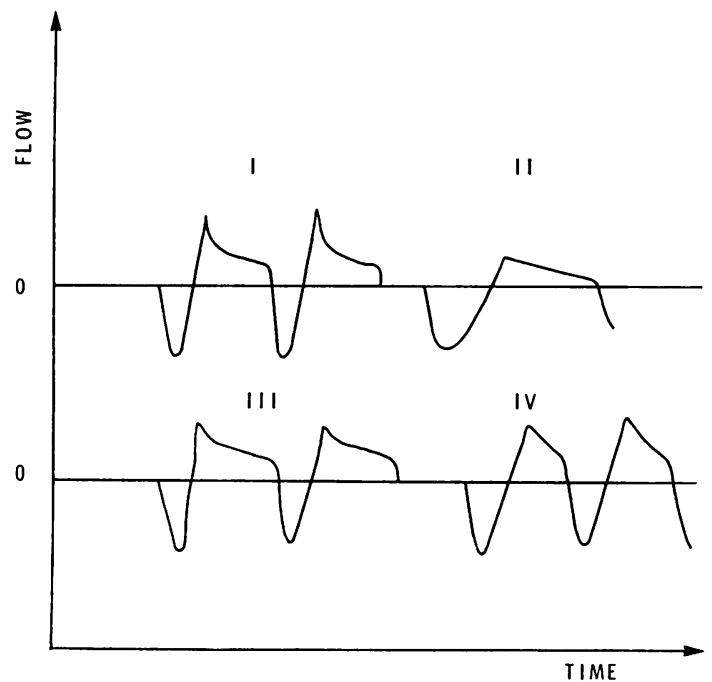

Fig 1 Tracings of tidal flow against time in four patients with airflow obstruction.

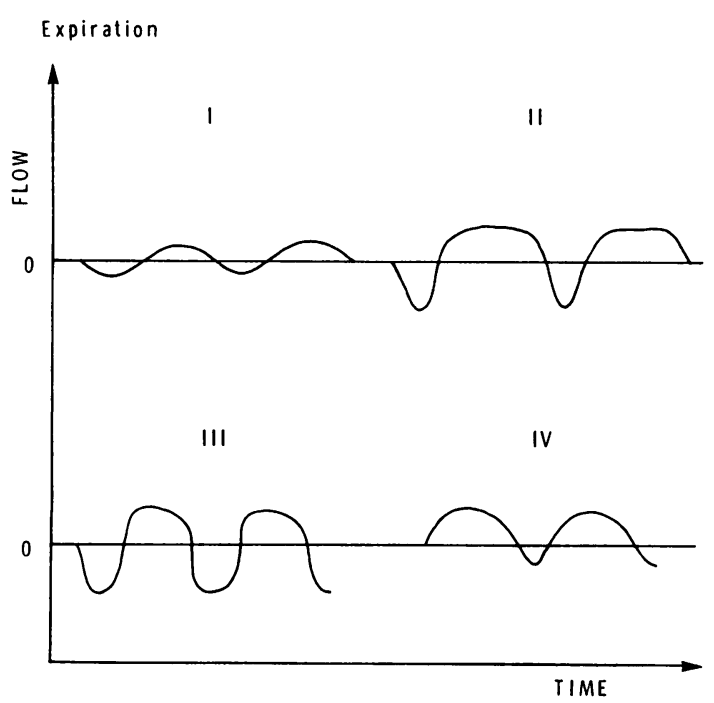

Fig 2 Tracings of tidal flow against time in three normal subjects $(I, I I$, and $I I I)$ and one patient with restrictive lung disease (IV). related well with $\mathrm{FEV}_{1} \%$ predicted, $\mathrm{FEV}_{1} / \mathrm{VC}^{2}$, and specific airway conductance (sGaw). The relationship between $\Delta V / V$ and $\Delta t / t$ is given in table $2 . \Delta t / t$ was slightly but significantly less than $\Delta \mathrm{V} / \mathrm{V}$. Either of these indices could be used to quantitate airways obstruction. There was no significant difference between average tidal peak flow rate, frequency of breathing, or proportion of breath time given to expiration, between the normal and obstructed patients. It was noticed that in individual patients with obstruction there was less variability in the expiratory flow pattern from breath to breath than in normal patients. When this variability in $\Delta t / t$ was analysed over the 10 breaths used for calculating the value of $\Delta t / t$ for each of the 24 normal subjects (mean $\mathrm{FEV}_{1} \%$ predicted $105 \pm 13 \cdot 3$ ), overall variance was 67.9 and coefficient of variation, $23 \%$. This contrasted with overall variance of $15 \cdot 1$ and coefficient of variation of $13 \%$ in the 23 most severely obstructed patients $\left(\mathrm{FEV}_{1}\right.$ less than $40 \%$ of predicted mean $19 \cdot 9 \pm 6 \cdot 7$ ).

In 20 of the 46 patients from group 2 in whom flow-volume loops were made, the expiratory flow achieved during quiet tidal breathing was greater that that achieved over the tidal range during a

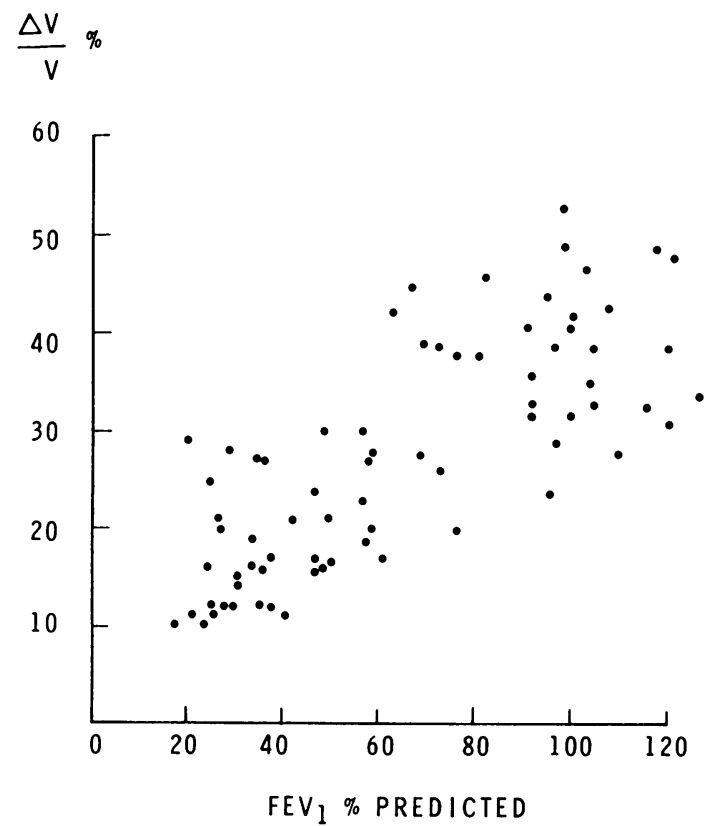

Fig 3 Graph showing correlation of $\Delta V / V \%$ with $F E V_{1} \%$ predicted in normal subjects and patients with airflow obstruction. 
maximum forced expiration from TLC (fig 6 pattern IV). Table 3 shows the indices of airways

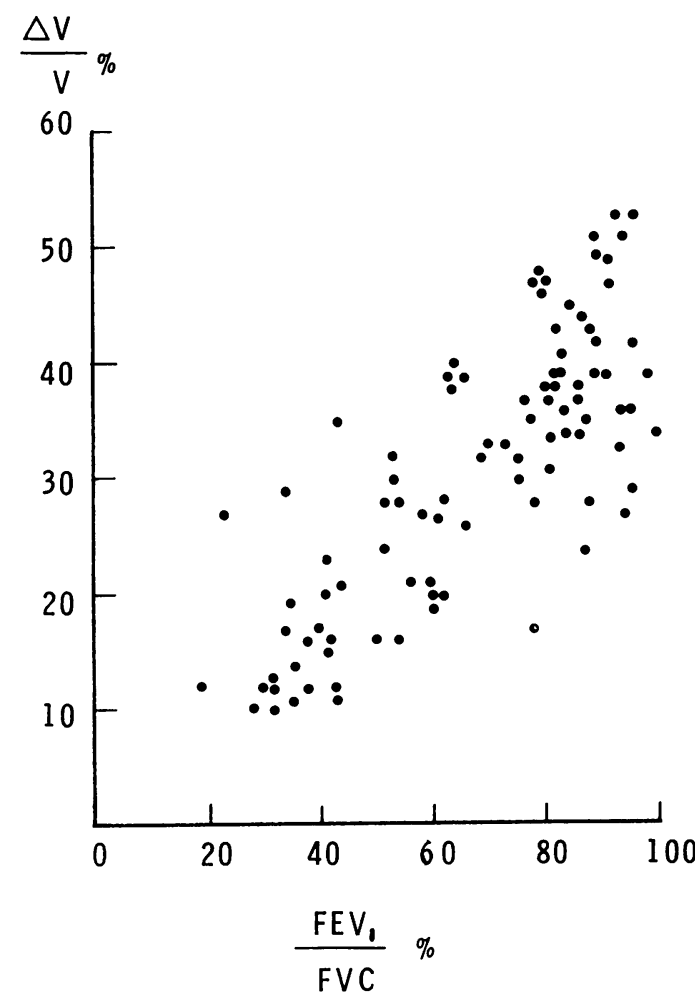

Fig 4 Graph showing correlation of $\Delta V / V \%$ with $F E V_{1} / V C$ expressed as a percentage in normal subjects, patients with airflow obstruction, and patients with restrictive lung disease. obstruction in the four groups of patients subdivided as shown in fig 6 . Through a sequence (I-IV) in which tidal flow approaches, equals, and exceeds maximum forced expiratory flow, there is evidence of a general increase in all the parameters of airflow obstruction measured.

\section{Discussion}

It appears that an analysis of the expiratory flow pattern against time can be used to quantitate the degree of airways obstruction. The correlations of the indices $\Delta \mathrm{V} / \mathrm{V}$ and $\Delta \mathrm{t} / \mathrm{t}$, with $\mathrm{FEV}_{1} \%$ predicted are comparable with those of sGaw versus $\mathrm{FEV}_{1} \%$ predicted and $\mathrm{sGaw}$ versus $\mathrm{FEV}_{1} / \mathrm{VC} \%$ (table 2) on the same patients. The advantage of this assessment of airway obstruction is that it requires minimum co-operation from the patient who has only to tolerate a mouthpiece and noseclip and is not required to perform any respiratory gymnastics. The technique is thus potentially valuable in the diagnosis of airflow obstruction in the very sick patient. We are investigating the sensitivity of the method in detecting acute changes in airflow obstruction as it might be useful in monitoring patients in status asthmaticus, particularly those in whom additional bronchoconstriction is induced by maximum forced expiratory manoeuvres.

It had been hoped that the analysis of expiratory flows during tidal breathing might give an estimate of airflow obstruction in patients being ventilated who are sedated but not paralysed or anaesthetised. Pilot studies have suggested that this will not be

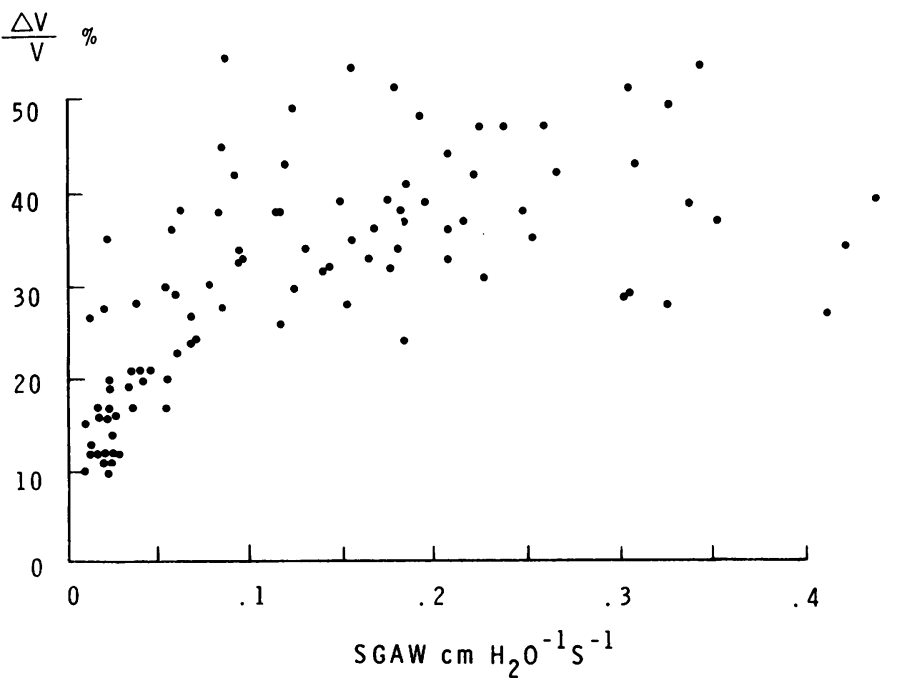

Fig 5 Graph showing correlation of $\Delta V / V \%$ with sGaw in normal subjects, patients with airflow obstruction, and patients with restrictive lung disease. 
Table 2 Correlations of $\Delta V / V \%$ and $\Delta t / t \%$ with other measurements of airflow obstruction

\begin{tabular}{|c|c|c|c|c|c|}
\hline & $\begin{array}{l}\text { Number } \\
\text { of patients }\end{array}$ & Slope & Intercept & $\begin{array}{l}\text { Correlation } \\
\text { coefficient }\end{array}$ & $p$ value \\
\hline 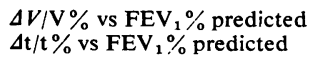 & $\begin{array}{l}71 \\
70\end{array}$ & $\begin{array}{l}0 \cdot 27 \\
0 \cdot 24\end{array}$ & $\begin{array}{l}9 \cdot 80 \\
9 \cdot 40\end{array}$ & $\begin{array}{l}0 \cdot 76 \\
0 \cdot 72\end{array}$ & $\begin{array}{l}<0.001 \\
<0.001\end{array}$ \\
\hline $\begin{array}{l}\Delta \mathrm{V} / \mathrm{V} \% \text { vs } \mathrm{FEV}_{1} / \mathrm{VC} \% \\
\Delta \mathrm{t} / \mathrm{t} \% \text { vs } \mathrm{FEV}_{1} / \mathrm{VC} \%\end{array}$ & $\begin{array}{l}95 \\
94\end{array}$ & $\begin{array}{l}0.42 \\
0.39\end{array}$ & $\begin{array}{l}2 \cdot 31 \\
1 \cdot 82\end{array}$ & $\begin{array}{l}0.77 \\
0.74\end{array}$ & $\begin{array}{l}<0.001 \\
<0.001\end{array}$ \\
\hline $\begin{array}{l}\Delta \mathrm{V} / \mathrm{V} \% \text { vs } \mathrm{SGaw} \\
\Delta \mathrm{t} / \mathrm{t} \% \text { vs } \mathrm{SGaw}\end{array}$ & $\begin{array}{l}94 \\
94\end{array}$ & $\begin{array}{l}61 \cdot 78 \\
60 \cdot 53\end{array}$ & $\begin{array}{l}22 \cdot 30 \\
19 \cdot 70\end{array}$ & $\begin{array}{l}0.62 \\
0.64\end{array}$ & $\begin{array}{l}<0.001 \\
<0.001\end{array}$ \\
\hline $\begin{array}{l}\Delta \mathrm{V} / \mathrm{V} \text { vs } \mathrm{Tex} / \mathrm{T} \text { total } \\
\Delta \mathrm{t} / \mathrm{t} \text { vs } \mathrm{Tex} / \mathrm{T} \text { total }\end{array}$ & $\begin{array}{l}97 \\
97\end{array}$ & $\begin{array}{l}0 \cdot 19 \\
0 \cdot 24\end{array}$ & $\begin{array}{l}64 \cdot 80 \\
65 \cdot 70\end{array}$ & $\begin{array}{l}0 \cdot 35 \\
0 \cdot 43\end{array}$ & $\begin{array}{l}<0.001 \\
<0.001\end{array}$ \\
\hline $\begin{array}{l}\text { SGaw vs } \mathrm{FEV} / \mathrm{VC} \% \\
\text { SGaw vs }^{\mathrm{FEV}} \text { predicted }_{1}\end{array}$ & $\begin{array}{l}93 \\
70\end{array}$ & $\begin{array}{l}0.004 \\
0.003\end{array}$ & $\begin{array}{l}0 \cdot 148 \\
0.065\end{array}$ & $\begin{array}{l}0.77 \\
0.82\end{array}$ & $\begin{array}{l}<0.001 \\
<0.001\end{array}$ \\
\hline$\Delta \mathrm{V} / \mathrm{V}$ vs $\Delta \mathrm{t} / \mathrm{t}$ & 97 & 0.97 & $3 \cdot 70$ & 0.93 & $<0.001$ \\
\hline
\end{tabular}

Table 3 Flow-volume loops in patients with airways obstruction mean values \pm one $S D$, with correlation coefficients and $p$ values of linear regressions against $\Delta V / V$

\begin{tabular}{|c|c|c|c|c|c|c|}
\hline & $\begin{array}{l}\text { Relationship of tidal fow } \\
\text { during quiet breathing to } \\
\text { that during maximal } \\
\text { forced expiration }\end{array}$ & $\begin{array}{l}\text { Number of } \\
\text { patients }\end{array}$ & $\begin{array}{l}F E V_{1} \% \text { predicted } \\
\text { correlation } \\
\text { coefficient }\end{array}$ & $F E V_{1} / V C \%$ & $\begin{array}{l}s \mathrm{saw} \\
\mathrm{cmH}_{2} \mathrm{O}^{-1} s^{-1}\end{array}$ & $\Delta V / V \%$ \\
\hline Pattern 1 & Much less & 6 & $\begin{array}{l}87 \pm 17 \\
0 \cdot 187 \text { (NS) }\end{array}$ & $\begin{array}{l}74 \pm 13 \\
0 \cdot 291(\mathrm{NS})\end{array}$ & $\begin{array}{l}0.149 \pm 0.057 \\
0.562(\mathrm{NS})\end{array}$ & $32 \pm 7$ \\
\hline Pattern II & Slightly less & 9 & $\begin{array}{l}63 \pm 20 \\
0.581(\mathrm{NS})\end{array}$ & $\begin{array}{l}61 \pm 12 \\
0 \cdot 293(\mathrm{NS})\end{array}$ & $\begin{array}{l}0.050 \pm 0.033 \\
0.743(\mathrm{p}<0.01)\end{array}$ & $26 \pm 10$ \\
\hline Pattern III & Same & 11 & $\begin{array}{l}45 \pm 17 \\
0.754(p<0.01)\end{array}$ & $\begin{array}{l}45 \pm 13 \\
0.768(p<0.01)\end{array}$ & $\begin{array}{l}0.041 \pm 0.038 \\
0.857(\mathrm{p}<0.001)\end{array}$ & $20 \pm 9$ \\
\hline Pattern IV & More & 20 & $\begin{array}{l}35 \pm 11 \\
0.483(\mathrm{p}<0.05)\end{array}$ & $\begin{array}{l}44 \pm 14 \\
0.639(\mathrm{p}<0.05)\end{array}$ & $\begin{array}{l}0.030 \pm 0.020 \\
0.740(\mathrm{p}<0.001)\end{array}$ & $20 \pm 8$ \\
\hline
\end{tabular}

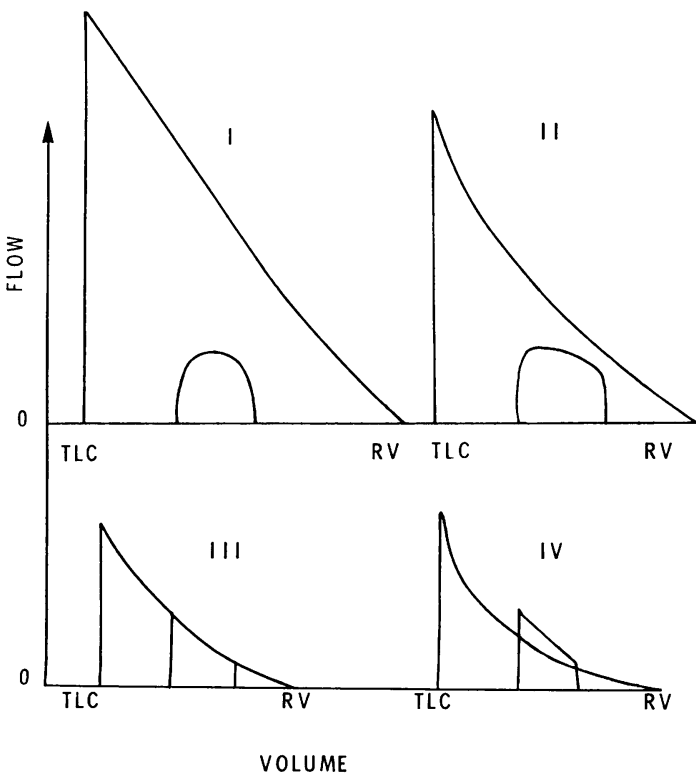

Fig 6 Schematic representation of patterns seen when flow is plotted against volume during tidal expiration and during maximally forced expiration from $T L C$. $I=$ normal, $I I, I I I, I V$ increasing severity of airflow obstruction. so. All patterns analysed in such ventilated (but not paralysed) patients showed a sharp rise in peak flow (low $\Delta \mathrm{V} / \mathrm{V}$ and $\Delta \mathrm{t} / \mathrm{t}$ ) whatever the degree of obstruction. This appears to be because either the sedation or the positive pressure during inspiration abolishes the postinspiratory tone of inspiratory musculature which appears to retard expiration in normal conscious subjects. ${ }^{45}$ Variable laryngeal braking of expiratory flow, which has been shown to occur in cats, ${ }^{67}$ cannot occur in intubated or tracheotomised patients. However, in cats the loss of upper airways slowing of expiratory flow when a tracheostomy is opened is immediately compensated for by extra postinspiratory diaphragmatic activity. ${ }^{8}$

The indices $\Delta \mathrm{V} / \mathrm{V}$ and $\Delta \mathrm{t} / \mathrm{t}$ do not include any expression of one important feature of tidal expiratory flow in obstructed breathing, which is that expiration ends abruptly before flow has declined to zero. The characteristic pattern is thus quadrilateral as seen in fig 2, and not sinusoidal as seen in normal subjects, or triangular as seen occasionally in apparently normal subjects. The normal subjects whose expiratory flow consistently followed a triangular pattern initially caused difficulty in analysis. A triangular pattern was also seen in some patients known to have airway obstruction, 
but who were in remission on the day of study. So it may be that a triangular expiratory flow pattern is a sensitive means of detecting mild airways narrowing. When $\Delta \mathrm{V} / \mathrm{V}$ or $\Delta \mathrm{t} / \mathrm{t}$ is used as a predictive index in conjunction with the visual appearance of the expiratory flow trace, one can say that there is significant airways obstruction present if the tracing shows a typical quadrilateral pattern with low variance. If $\Delta \mathrm{V} / \mathrm{V}$ is less than $25 \%$ there is severe airways obstruction.

It is interesting to speculate why the expiratory flow pattern should have a quadrilateral shape in patients with airflow obstruction. We would like to consider each part of the flow pattern in turn.

\section{RAPID RISE OF EXPIRATORY FLOW TO ITS PEAK}

In normal subjects during expiration the peak flow is reached approximately one-third of the way through the expiratory phase. ${ }^{4}$ This pattern of flow during spontaneous expiration suggests that the activity of inspiratory muscles subsides slowly during expiration. This has been shown by electromyographic findings and by the time course of oesophageal pressure during spontaneous expiration. ${ }^{4-12}$ If the expiration is completely passive-that is, inspiratory muscle activity ceases abruptly at the end of inspiration-and the chest is permitted to recoil freely one would expect pleural pressure to increase sharply and flow to rise sharply to a peak, there being little inertia in the system. ${ }^{4}$ In the few patients with airflow obstruction in whom we have measured oesophageal pressures ${ }^{13}$ the pleural pressure does increase fairly sharply to zero or slightly positive values at the onset of expiration, and stays at this pressure till near the end of expiration. Flow as we have shown rises rapidly to a peak. Although we do not have electromyographic data in patients with airflow obstruction to support this speculation, we suggest that abrupt cessation of inspiratory muscle activity at the beginning of expiration allows resultant lung and chest wall recoil pressures to drive expiration freely. In patients with severe airflow obstruction and/or emphysema (with low lung recoil pressures) if reasonable flows are to be achieved it is necessary to use all or most of the recoil pressure to drive flow and not to oppose it by inspiratory muscle activity. The correlation we have shown between $\Delta t / t$ (and $\Delta V / V)$ and the severity of airflow obstruction as determined by other methods is probably the result of muscle activity stopping at the end of inspiration in a graded fashion-abruptly in very severe obstruction, more gradually in less severe obstruction, and still more gradually in normal subjects and patients with restrictive disease.

PHASE OF GRADUAL DECREASE OF FLOW THROUGHOUT MOST OF EXPIRATION

We suggest this occurs in a completely passive expiration in parallel with the known gradual decrease in resultant lung and chest wall recoil pressures with decrease in lung volume. The re- o sultant pressure should reach zero at FRC when lung and chest wall recoil pressures are equal and opposed.

SHARP DROP OF FLOW RATE TO ZERO

If expiration is ended before the FRC that would obtain in the absence of airflow obstruction is reached, there will still be measurable flow at this volume. Expiration ends not because of a balance of pressure reached smoothly but abruptly while there is still recoil pressure available to drive flow because of ventilatory drive demanding the next inspiration. An examination of the tidal flowvolume tracings shows that these have the same quadrilateral appearance. Pattern III in fig 6 in which the tidal flows are the same as the forced maximal flows at the same volumes is a familiar pattern in severe airflow obstruction. Mead et al $^{14}$ in their analysis of the forced flow-volume loop have shown that once dynamic compression of airways downstream of the equal pressure points has occurred within the chest, the effective driving pressure for maximum flow is static recoil of the lung.

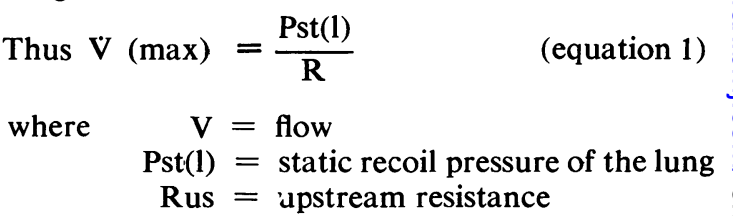
In pattern III of fig 6 , the tidal flows may be the same as the maximum flows because dynamic compression is occurring in tidal breathing as well $N$ and the flow is determined by the same factorsthat is, static lung recoil and upstream resistance (equation 1).

For dynamic compression to occur intrapleural pressure must be positive. In the few patients with 0 airflow obstruction that we have studied during $\mathbb{D}$ quiet spontaneous breathing, oesophageal pressure does often become slightly positive early in expiration. However the usual pressures we have $\frac{O}{\mathbb{D}}$ seen have been 1 to $2 \mathrm{cmH}_{2} \mathrm{O}$ and we have not $\stackrel{?}{\stackrel{8}{*}}$ observed pressures greater than $5 \mathrm{cmH}_{2} \mathrm{O}$. We have $\stackrel{\mathbb{Q}}{\varrho}$ certainly seen this typical quadrilateral expiratory flow pattern in many breaths in which oesophageal 
pressure did not exceed zero. Mead and his coworkers ${ }^{14}$ suggest that in normal subjects dynamic compression of airways within the chest at $65 \%$ $\mathrm{VC}$ begins when the pleural pressure is $12 \mathrm{cmH}_{2} \mathrm{O}$ above atmospheric. Although in patients with increased airways resistance or very low lung recoil pressures, compression may occur at lower intrapleural pressures, it does not seem from our preliminary data on pleural pressures that the only possible explanation of the similar flow rates in quiet and forced expirations is dynamic compression. If in fully relaxed passive tidal expiration airways are not being compressed:

$$
\mathbf{V}=\frac{\text { Pst(1) }+ \text { Pst (chest wall) }}{\mathrm{R} \text { total }}
$$

(equation 2)

where Pst(chest wall) $=$ static recoil pressure of chest wall

$\mathrm{R}$ total $=$ total resistance of airways, lung, and chest wall.

In trained normal subjects flows during relaxed expiration from TLC are less than maximally forced ones. ${ }^{15}{ }^{16}$ In normal subjects, upstream resistance is small and in some of the tidal range chest wall recoil is opposing lung recoil, so one would expect the flow of equation 1 to be greater than the flow of equation 2. However in patients with airways obstruction most of the resistance resides in the upstream segment, so the total resistance (denominator equation 2) may be of the same order as the upstream resistance (denominator equation 1). Because of hyperinflation in airways obstruction chest wall recoil may be inwards adding to lung recoil in driving flow in tidal expiration, so that the numerator of equation 2 would be greater than that of equation 1 . It is thus conceivable that flows of equation 1 and equation 2 could be of the same order in airways obstruction. Tidal flow (equation 2) might even be greater than forced maximal flow (equation 1) as in pattern IV (fig 6).

Other possible explanations for a tidal flow that is greater than maximally forced flow are as follows:

1 That the real lung volumes are not the same because of alveolar gas compression in the forced manoeuvre. The lung volume measured at the mouth is thus greater than that within the lungs (Boyle's law). The forced expiratory flow-volume curve corrected for compression would be shifted to the right.

2 If dynamic compression is occurring in both cases, tidal expiration is then virtually a partial forced flow-volume curve and flow is determined by the relationship between static recoil pressure of the lung and upstream resistance. Because of the hysteresis characteristics of the pressurevolume curve, the recoil pressures of the lung after a deep inspiration will be less at the same lung volumes than during the tidal expiration. This could result in flows being less in the maximally forced expiration from TLC than in tidal expiration in patients with airways obstruction. ${ }^{17} 18$

3 It may be that there is unequal distribution of airways narrowing and that during tidal breathing a greater contribution is coming from the wellventilated parts of the lung than at the same lung volume during a maximally forced expiration from TLC.

We would like to thank the patients and volunteers who took part in this study, Dr $\mathbf{R}$ Marshall for many helpful discussions of the data, Dr M Benson for reading the manuscript critically, and Mrs J Broadis and Mrs D Russell for secretarial help. We are also grateful to Dr John Macfarlane and Mr Richard Madgwick for making the measurements in ventilated patients.

\section{References}

1 Dubois AB, Botelho SY, Comroe JH. A new method for mesuring airway resistance in man using a body plethysmograph: values in normal subjects and in patients with respiratory diseases. $J$ Clin Invest 1956; 35:327-35.

2 Dubois AB, Botelho SY, Bedell CN, Marshall R, Comroe JH. A rapid plethysmographic method for measuring thoracic gas volumes: a comparison with a nitrogen washout method for measuring functional residual capacity in normal subjects. J Clin Invest 1956; 35:322-6.

3 Bates DV, Macklem PT, Christie RV. Respiratory function in disease. Second edition. Philadelphia: WB Saunders, 1971; 93-4.

4 Campbell EJM, Agostini E, Newsom Davis J. The respiratory muscles, mechanics and neural control. Second edition. London: Lloyd-Luke, 1970; 96-8.

5 Marshall R. Relationships between stimulus and work of breathing at different lung volumes. J Appl Physiol 1962; 17:917-21.

6 Gautier H, Remmers JE, Bartlett D. Control of the duration of expiration. Respir Physiol 1973; 18:205-21.

7 Bartlett D, Remmers JE, Gautier H. Laryngeal regulation of respiratory airflow. Respir Physiol 1973; 18:194-204.

8 Remmers JE, Bartlett D. Reflex control of expiratory airflow and duration. J Appl Physiol 1977; 42:80-7.

9 Green JH, Howell JBL. Correlation of intercostal 
muscle activity with respiratory airflow in conscious human subjects. J Physiol (Lond) 1959; 149:471-6.

10 Agostinin E, Sant'Ambrogio G, Del Portillo Carrasco $\mathrm{H}$. Electromyography of the diaphragm in man and transdiaphragmatic pressure. J Appl Physiol 1960; 15:1093-7.

11 Petit JM, Milic-Emili J, Delhez L. Role of the diaphragm in breathing in conscious normal man: an electromyographic study. J Appl Physiol 1960; 15:1101-6.

12 Lourenço RV, Mueller ED. Qualification of electrical activity in the human diaphragm. J Appl Physiol 1967; 22:598-600.

13 Milic-Emili J, Mead J, Turner, JM, Glauser EM. Improved technique for estimating pleural pressure from oesophageal balloons. J Appl Physiol $1964 ; 19: 207-11$.
14 Mead J, Turner JM Macklem PT, Little JB. Significance of the relationship between lung recoil and maximum expiratory flow. J Appl Physiol 1967; 22:95-108.

15 Pierce JA. Studies of free collapse in the intact human lung. J Lab Clin Med 1959; 54:96106.

16 McIlroy MB, Tierney DF, Nadel JA. A new method for measurement of compliance and resistance of lungs and thorax. J Appl Physiol $1963 ; 18: 424-7$.

17 Vincent NJ, Knudson R, Leith DG, Macklem PT, Mead J. Factors influencing pulmonary resistance. J Appl Physiol 1970; 29:236-43.

18 Gayrard P, Orehek J, Grimaud C, Charpin J. Bronchoconstriction effect of a deep inspiration in patients with asthma. Am Rev Respir Dis $1975 ; 111: 433-9$. 